\title{
Classification analysis of young stroke in zhuhai city, China
}

\author{
Zhendong $\mathrm{Li}^{1{ }^{+*}}$, Jun Wang ${ }^{2 \dagger}$, Shijian Luo ${ }^{1}$, Jinqi Wei ${ }^{1}$ and Xiangyang $\mathrm{Hu}^{1}$ \\ *Correspondence: lizdsysu@163.com \\ ${ }^{\dagger}$ These authors contributed equally to this work. \\ 'Department of Neurology, The Fifth Affiliated Hospital of Sun Yat-Sen University, Zhuhai, China. \\ ${ }^{2}$ Department of Neurology, Coal General Hospital, Beijing, China.
}

\begin{abstract}
Background: The morbidity and mortality rates in young Chinese stroke patients have increased, and the appropriate classification of stroke is very important to identifying the cause, pathogenesis, severity, outcome, and preventive and therapeutic strategies. This study sought to analyse the young stroke subtype in a coastal city Zhuhai of southern China.

Methods: Hospitalised young stroke patients in the two largest local hospitals were retrospectively analysed from July 2002 to July 2009. The percentage of every stroke subtype was calculated.

Results: A total of 416 young stroke patients (age 18-45 years) were included. There were 225 (54.1\%) cases of ischemic stroke (IS), $145(34.9 \%)$ cases of intracerebral haemorrhage (ICH), 38 (9.1\%) cases of subarachnoid haemorrhage (SAH), and 8 (1.9\%) cases of mixed stroke (MS). Cases of IS were divided into four groups using the OCSP criteria: 15 (6.7\%) total anterior circulation infarcts (TACI), 117 (52.0\%) partial anterior circulation infarcts (PACI), 61 (27.1\%) lacunar infarcts (LACI ), and 32 (14.2\%) posterior circulation infarcts (POCI). Cases of IS were divided into five groups using the TOAST criteria: 14 (6.2\%) cases of large-artery atherosclerosis (LAA), 15 (6.7\%) cases of cardioembolism (CE), 108 (48 \%) cases of small-artery occlusion (SAO), 16 (7.1\%) cases of stroke of other determined aetiologies (SOE), and 72 (32\%) cases of stroke of undetermined aetiology (SUE).

Conclusions: The results suggested that within the locality, the majority of cases of young stroke were IS and ICH, and the minority were SAH and MS; additionally, the most common IS subtypes were PACI, LACI or SAO and SUE, which could contribute to the local prevention and control of stroke.
\end{abstract}

Keywords: Young stroke, subtype, OCSP, TOAST, China

\section{Introduction}

In recent years, studies have shown that morbidity and mortality rates in young Chinese stroke patients have increased $[1,2]$ and the hospitalisation rates of young American stroke patients have also tended to rise [3]. Young adults with stroke have longer expected survival rates relative to older people with stroke, and young adults are more likely to be gainfully employed after stroke occurs than the very elderly. Therefore, more attention should be paid to the prevention and control of young stroke [4]. The aetiology of stroke is heterogeneous, and the aetiology, risk factors, and prognosis of young stroke are different from those of older stroke [5]. Additionally, variations in the aetiology and risk factors in different areas lead to variant stroke incidences and subtypes $[6,7]$. Therefore, the proper classification of stroke is critical to indicate the cause, pathogenesis, severity, outcome and preventive and therapeutic strategies $[\mathbf{8}, \mathbf{9}]$. The city of Zhuhai is an emerging economic power with a subtropical marine climate on the coast of southern China. Its population has increased yearly, and inland immigrants and migrant workers account for more than $80 \%$ of the population, most of whom are young and postadolescent adults. Currently, the subtypes of young stroke within this region remain unclear. This study aimed to analyse these subtypes in order to facilitate the local prevention and control of stroke.

\section{Methods \\ Patients}

Young patients (aged between 18 and 45 years) with first-ever acute stroke who were hospitalised at our hospital and at Zhuhai People's Hospital (the two largest local hospitals) from July 2002 to July 2009 were included in the study. The diagnosis of stroke met the World Health Organization criteria [10] and was verified by brain CT/MRI or lumbar puncture. Traumatic strokes, intracranial tumours or infections, demyelinating lesions of the brain, concurrent severe insufficiencies of internal organs, and mutilations or malformations of limbs originated by other causes were excluded. The patients' medical records were retrospectively analysed by an attending neurologist specialising in stroke. The data extracted from the case history, medical and neurological examinations, laboratory reports (routine blood examinations, blood glucose, blood lipids, liver and renal function tests, blood electrolytes, blood C-reactive proteins, erythrocyte sedimentation rates, hemorheology and cerebrospinal fluid), electrocardiograms and imaging tests (chest x-ray, Cranial CT/CTA, Cranial MRI/MRA, Cranial DSA, colour Doppler ultrasonography of the carotid/vertebral artery and heart, transcranial Doppler) were entered into a database. The 
Li et al. Neuroscience Discovery 2013,

Table 1. Baseline characteristics $(n=416)$.

\begin{tabular}{lc}
\hline Parameter & Value \\
\hline Age & - \\
Range (years) & $18-45$ \\
Mean (years \pm S.D ) & $37.17 \pm 0.70$ \\
Men $[n(\%)]$ & $227(66.60)$ \\
Risk factors or causes of stroke $[n(\%)]$ & - \\
Hypertension & $145(34.86)$ \\
Diabetes mellitus & $31(7.45)$ \\
Smoking & $107(25.72)$ \\
Drinking & $51(12.26)$ \\
Dyslipidaemia & $188(45.19)$ \\
Cardioembolism & - \\
Coronary heart disease & $5(1.20)$ \\
Rheumatic heart disease & $9(2.16)$ \\
Atrial myxoma & $1(0.24)$ \\
Blood hyperviscosity & $17(4.09)$ \\
Arteriovenous malformation of brain & $13(3.13)$ \\
Vasculitis & $5(1.20)$ \\
Brain aneurysm & $5(1.20)$ \\
Puerperium & $2(0.48)$ \\
Leukaemia & $1(0.24)$ \\
Family history & - \\
Hypertension & $41(9.86)$ \\
Stroke & $16(3.85)$ \\
Cardiac disease & $2(0.48)$ \\
\hline
\end{tabular}

study was approved by the local research ethics committee.

\section{Definitions}

Historically, atherosclerosis was considered to be the cause of stroke when a patient presented evidence on a blood vessel image or exhibited two and more atherosclerosis risk factors for atherosclerosis without another determined aetiology [11]: hypertension, diabetes mellitus, smoking/ drinking, dyslipidaemia, coronary heart disease, transient ischemic attack, and family history. Other causes of stroke were determined according to the specific history, CT/MRI detection, cerebrovascular image, colour Doppler ultrasonography of the heart, and blood tests and so on. Hypertension was defined as having a history of hypertension or at least two different records of systolic blood pressure $\geq 140 \mathrm{~mm} \mathrm{Hg}$ / diastolic blood pressure $\geq 90 \mathrm{~mm} \mathrm{Hg}$ after the acute phase of stroke. Diabetes mellitus was defined as having a history of diabetes mellitus or a morning fasting glucose $>7.0 \mathrm{mmol}$ $\Lambda$ and a random glucose/two-hour postprandial glucose $>$ $11.1 \mathrm{mmol} / \mathrm{L}$ after the acute phase. Smoking was defined as a history of cigarette use $>5$ years, the current use of $>10$ cigarettes/day, or the cessation of smoking within the past year. Drinking was defined as a history of drinking $>5$ years or a current habit of drinking $>500 \mathrm{~g}$ /week. Dyslipidaemia was defined as a total fasting cholesterol $>5.7 \mathrm{mmol} \Lambda$, fasting triglyceride $>1.7 \mathrm{mmol} / \mathrm{L}$, high-density lipoprotein cholesterol $<1.0 \mathrm{mmol} / \mathrm{L}$, low-density lipoprotein cholesterol $>3.2 \mathrm{mmol}$ $\Lambda$, lipoprotein $(\mathrm{a})>300 \mathrm{mg} / \mathrm{L}$, or apoprotein $\mathrm{A} 1<1.0 \mathrm{~g} / \mathrm{L}$, and apoprotein B100 >1.0 g/L.

\section{Classification of stroke}

Stroke was classified as either ischemic stroke (IS), intracerebral haemorrhage (ICH), subarachnoid haemorrhage (SAH), or mixed stroke (MS). Then, IS was divided into subtypes by two independent consultant neurologists according to the Oxfordshire Community Stroke Project (OCSP) classification and the Trial of Org 10172 in Acute Stroke Treatment (TOAST) classification [12,13], respectively. The OCSP classification includes the total anterior circulation infarcts (TACI), partial anterior circulation infarcts (PACl), posterior circulation infarcts $(\mathrm{POCl})$ and lacunar infarcts (LACI). The TOAST classification includes large-artery atherosclerosis (LAA), cardioembolism $(C E)$, small-artery occlusion (SAO), stroke of other determined aetiology (SOE), and stroke of undetermined aetiology (SUE).

\section{Statistical analysis}

SPSS 13.0 (SPSS Inc., Chicago, IL, USA) was employed in our study. Measurement data were expressed as mean \pm S.D, and numeration data were expressed as the number of cases or as percentages (\%). The chi-square test $(x 2)$ was also used when appropriate, and statistical significance was set as $P<0.05$.

\section{Results \\ Baseline characteristics}

A total of 416 Han Chinese patients with stroke were enrolled in this study. Their ages ranged between 18 and 45 years (mean age $37.17 \pm 0.70$ years), and 227 of them were men $(66.6 \%)$. All of the patients underwent blood tests, electrocardiograms, chest x-rays and cranial CT/MRI scans; 62 patients underwent CTA or DSA; 37 patients underwent a transcranial Doppler; 100 patients underwent colour Doppler ultrasonography of the heart; 117 patients underwent colour Doppler ultrasonography of the carotid/vertebral artery; and 23 patients underwent lumbar puncture. The risk factors and causes of stroke are shown in (Table 1).

\section{Subtypes of stroke}

A total of 225 cases of IS (54.1\%), 145 cases of ICH (34.9\%), 38 cases of SAH (9.1\%) and 8 cases of MS (1.9\%) were identified among the patients. All of the patients were divided into one of three age groups: 18 to 28 years, 29 to 39 years, and 40 to 45 years. The number of the patients in each group was 64 (15.4\%), 146 (35.1\%), and 206 (49.5\%), respectively, and the ratio of the sexes was $2.1: 1,1.8: 1$ and $2: 1$, respectively. Differences were observed in the occurrence of IS $(P=0.000)$, $\mathrm{ICH}(P=0.014)$ and MS $(P=0.020)$ between the age groups. The occurrences of IS and ICH tended to increase with age and were most common in patients between 40 and 45 years old, and IS increased more obviously. MS was the most common in 18- to 28-year-olds. However, the distributional difference of SAH was not statistically significant $(P=0.138)$ between the age groups (Table 2 ).

\section{Subtypes of IS}

The patients (155 men, 70 women) with IS were between 18 and 45 years old (mean age of $37.24 \pm 1.17$ years). According to the OCSP criteria, there were 15 cases of TACI (6.7\%), 117 cases of $\mathrm{PACl}(52.0 \%), 61$ cases of $\mathrm{LACl}(27.1 \%)$ and 32 cases 
Li et al. Neuroscience Discovery 2013,

http://www.hoajonline.com/journals/pdf/2052-6946-1-2.pdf

doi: 10.7243/2052-6946-1-2

Table 2. Distribution of stroke type in different age groups.

\begin{tabular}{|c|c|c|c|c|c|}
\hline \multirow{2}{*}{ Stroke type } & \multicolumn{3}{|c|}{$\mathrm{N}$} & \multirow{2}{*}{$\chi^{2}$} & \multirow{2}{*}{$\mathrm{P}$} \\
\hline & $18-28 \mathrm{y}$ & $29-39 y$ & $40-45 y$ & & \\
\hline IS & 21 & 21 & 130 & 19.094 & 0.000 \\
\hline $\mathrm{ICH}$ & 31 & 31 & 60 & 8.469 & 0.014 \\
\hline SAH & 8 & 8 & 13 & 3.960 & 0.138 \\
\hline MS & 4 & 4 & 3 & 7.778 & 0.020 \\
\hline
\end{tabular}

Abbreviations:

IS=ischemic stroke

ICH =intracerebral haemorrhage

$\mathrm{SAH}=$ subarachnoid haemorrhage

$\mathrm{MS}=$ mixed stroke

Table 3. Sex distribution of the ischemic stroke subtypes.

\begin{tabular}{lcccc}
\hline Subtype & Male(n) & Female(n) & $\boldsymbol{x}^{2}$ & $\boldsymbol{P}$ \\
\hline OCSP & - & - & - & - \\
TACI & 11 & 4 & 0.148 & 0.700 \\
PACI & 84 & 33 & 0.960 & 0.327 \\
LACI & 41 & 20 & 0.110 & 0.741 \\
POCI & 19 & 13 & 1.576 & 0.209 \\
TOAST & - & - & - & - \\
LAA & 5 & 9 & 5.378 & 0.020 \\
CE & 13 & 2 & 3.464 & 0.063 \\
SAO & 62 & 46 & 4.489 & 0.034 \\
SOE & 13 & 3 & 2.123 & 0.145 \\
SUE & 52 & 20 & 2.795 & 0.095 \\
\hline
\end{tabular}

\section{Abbreviations:}

OCSP = Oxfordshire Community Stroke Project

$\mathrm{TACI}=$ total anterior circulation infarcts

PACI $=$ partial anterior circulation infarcts

LACI= lacunar infarcts

POCI $=$ posterior circulation infarcts

TOAST $=$ Trial of Org 10172 in Acute Stroke Treatment

LAA $=$ large-artery atherosclerosis

$\mathrm{CE}=$ Cardioembolism

$\mathrm{SAO}=$ small-artery occlusion

$\mathrm{SOE}=$ stroke of other determined aetiology

$\mathrm{SUE}=$ stroke of undetermined aetiology

of POCI (14.2\%) among the patients. According to the TOAST criteria, there were 14 cases of LAA $(6.2 \%), 15$ cases of CE (6.7\%), 108 cases of SAO (48\%), 16 cases of SOE (7.1\%) and 72 cases of SUE (32\%) among the patients. Every OCSP subtype occurred more often in men than in women and increased with age, but not with significant differences (Table 3,4). In addition to LAA, the other TOAST subtypes also occurred more often in men than in women, and the sex differences in LAA $(P=0.020)$ and SAO $(P=0.034)$ were statistically significant (Table 3). Additionally, the number of SOE cases reported less in 29- to 39-year-olds was less than that in 18- to 28-year-olds and in 40- and 45-year-olds. The remainder of the TOAST subtypes generally increased with age, but only the age group distributions of SAO $(P=0.023)$ and SOE $(P=$ 0.007 ) were significantly different (Table 4).

\section{Discussion}

Constitutive characteristics of young stroke subtypes Generally, IS is the main form of stroke, and haemorrhagic
Table 4. Distribution of the ischemic stroke subtypes in different age groups.

\begin{tabular}{lccccc}
\hline Subtype & $\mathbf{1 8 - 2 8} \mathbf{y}$ & $\mathbf{2 9 - 3 9} \mathbf{y}$ & $\mathbf{4 0 - 4 5} \mathbf{y}$ & $\boldsymbol{x}^{\mathbf{2}}$ & $\boldsymbol{P}$ \\
\hline OCSP & - & - & - & - & - \\
TACI & 2 & 6 & 7 & 0.866 & 0.649 \\
PACI & 13 & 39 & 65 & 1.048 & 0.592 \\
LACI & 3 & 19 & 39 & 2.374 & 0.305 \\
POCI & 3 & 10 & 19 & 0.047 & 0.977 \\
TOAST & - & - & - & - & - \\
LAA & 3 & 3 & 8 & 2.532 & 0.282 \\
CE & 1 & 7 & 7 & 1.830 & 0.400 \\
SAO & 6 & 29 & 73 & 7.525 & 0.023 \\
SOE & 5 & 2 & 9 & 10.064 & 0.007 \\
SUE & 7 & 29 & 36 & 4.347 & 0.114 \\
\hline
\end{tabular}

Abbreviations:

OCSP $=$ Oxfordshire Community Stroke Project

TACI $=$ total anterior circulation infarcts

PACI $=$ partial anterior circulation infarcts

$\mathrm{LACI}=$ lacunar infarcts

POCI $=$ posterior circulation infarcts

TOAST $=$ Trial of Org 10172 in Acute Stroke Treatment

LAA $=$ large-artery atherosclerosis

$\mathrm{CE}=$ Cardioembolism

$\mathrm{SAO}=$ small-artery occlusion

$\mathrm{SOE}=$ stroke of other determined aetiology

$\mathrm{SUE}=$ stroke of undetermined aetiology

stroke is the second most common form; this pattern is also observed in cases of young stroke [14]. However, a disparity exists regarding the stroke types in different regions due to the geographic incidence of stroke $[6,7]$. Typically, stroke morbidity in China was higher in the North than in the South, but ICH occurred more often in the South than in the North $[6,15]$. However, the incidence of ICH was lower in the economically emerging areas on the southern coast, such as Shanghai, Guangdong, and Hong Kong. This trend may be due to increases in the risk factors for IS, such as atherosclerosis, diabetes mellitus and overweight, as a result of the relatively developed economy and influence of the western lifestyle in these areas [6]. In addition, this trend may be correlated with climate, living environment, eating habits and genetic factors. It should be noted that site of bleeding in ICH affect the patients' outcome. A previous study confirmed that the in-hospital mortality rates were multiple topographic $\mathrm{ICH}$ $>$ Primary intraventricular haemorrhage $>$ brainstem $\mathrm{ICH}>$ thalamic ICH > lobar ICH > cerebellar ICH > internal capsule/ basal ganglia ICH [16]. In foreign countries, IS, SAH and ICH accounted for $21.0 \%$ and $77.9 \%, 9.6 \%$ and $55.4 \%$, and $3.7 \%$ and $38.5 \%$ of all young strokes, respectively [14]. A Chinese multicentre study of hospital patients (age range of 18 to 45 years) showed that $63.6 \%$ of cases exhibited IS and $36.4 \%$ exhibited haemorrhagic stroke [17]. There were four stroke types in our study; IS was present in more than half of cases, $\mathrm{ICH}$ accounted for more than one-third of cases, SAH was present in less than one-tenth of cases, and MS was the least prevalent. These results indicated that the main form of young stroke in this locality was IS and the second was ICH, which 
Li et al. Neuroscience Discovery 2013,

http://www.hoajonline.com/journals/pdf/2052-6946-1-2.pdf

doi: 10.7243/2052-6946-1-2

Table 5. TOAST classification of young stroke in different studies.

\begin{tabular}{|c|c|c|c|c|c|c|c|c|c|}
\hline \multirow{2}{*}{ Country/region } & \multirow{2}{*}{ Time } & \multirow{2}{*}{ Study design } & \multirow{2}{*}{ Age (yr) } & \multirow{2}{*}{ Patients (n) } & \multicolumn{5}{|c|}{ Stroke subtype (\%) } \\
\hline & & & & & LAA & $\mathrm{CE}$ & SAO & SOE & SUE \\
\hline Taiwan & 2002 & Hospital-based Retrospective & $18-45$ & 264 & 7.2 & 17.8 & 20.5 & 22.3 & 23.5 \\
\hline Italy, Turin & 2004 & Hospital-based Prospective & $16-49$ & 273 & 16 & 24 & 17 & 19 & 24 \\
\hline Switzerland, Bern & 2005 & Hospital-based Prospective & $16-45$ & 203 & 4 & 24 & 9 & 30 & 33 \\
\hline Iran & 2006 & Hospital-based Prospective & $15-45$ & 124 & 6.45 & 54 & 2.4 & 8.1 & 28.2 \\
\hline Italy, Rome & 2006 & Hospital-based Prospective & $14-47$ & 394 & 12 & 34 & 2.5 & 13 & 23.8 \\
\hline China Guangzhou & 2008 & Hospital-based Retrospective & $18-44$ & 41 & 26.8 & 7.3 & 7.3 & 26.8 & 31.8 \\
\hline China Beijing & 2008 & Hospital-based Retrospective & $16-45$ & 243 & 22.2 & 12.8 & 16 & 7.0 & 42 \\
\hline China Anhui & 2009 & Hospital-based Prospective & $\leq 45$ & 78 & 22.5 & 12.5 & 16 & 9 & 40 \\
\hline Finland Helsinki & 2009 & Hospital-based Prospective & $15-49$ & 731 & 8.2 & 17.9 & 13.5 & 24.6 & 35.7 \\
\hline Finland Helsinki & 2010 & Hospital-based Prospective & $15-49$ & 807 & 8.4 & 18.7 & 13.9 & 25.9 & 33.1 \\
\hline Thailand & 2011 & Hospital-based Prospective & $16-50$ & 99 & 11.1 & 13.1 & 23.2 & 22.2 & 25.3 \\
\hline Finland Helsinki & 2011 & Hospital-based Prospective & $15-49$ & 655 & 5.6 & 18.0 & 13.6 & 29.3 & 33.4 \\
\hline Germany & 2012 & Hospital-based Prospective & $19-45$ & 104 & 10.6 & 21.2 & 9.6 & 19.2 & 39.4 \\
\hline Italy Ferrara & 2012 & Population-based Prospective & $15-44$ & 24 & 16.6 & 29.2 & 20.8 & 29.2 & 4.2 \\
\hline UK & 2012 & Hospital-based Prospective & $16-55$ & 106 & 6 & 28 & 11 & 22 & 33 \\
\hline
\end{tabular}

was in accordance with the reported stroke occurrence in coastal areas in southern China [6]. In our study, the number of men exceeded that of women in the four stroke types, and the occurrences of IS and ICH increased with age, which fit the general rules of stroke occurrence. However, the age or sex differences of most IS subtypes were non-significant when IS was reclassified for analysis. It was possible that the reduction of patients in each IS subtype attenuated the statistical efficiency. For SAH and MS, the statistical results might also be insufficient in reflecting the age-related characteristics of occurrence due to the lower number of patients studied.

It is worth mentioning that MS was considered to be an independent form of stroke, and it referred to the simultaneous or successive occurrence (within 24 hours) of IS and ICH in different areas of the patient's brain [18]. The international literature has rarely reported on MS. A previous report from China showed that MS accounted for $11.6 \%$ of cases (8 MS cases in 115 stroke autopsies) [18]. MS accounted for $1.9 \%$ of cases in our study, which suggested that MS was uncommon in the young population studied.

\section{Subtype constituents of IS}

The OCSP classification can predict the severity and prognosis of stroke $[19,20]$, but it has seldom been applied to young stroke research. Nedeltchev et al., [21] prospectively studied 203 cases of young IS (in 16- to 45-year-olds), in which the number of OCSP subtypes was $\mathrm{PACl}>\mathrm{POCl}>\mathrm{LACl}>\mathrm{TACl}$ and the severity of nervous impairment was $\mathrm{TACl}>\mathrm{PACl}>\mathrm{POCl}$ $>\mathrm{LACl}$. The $\mathrm{LACl}$ exhibited the best three-month outcome, followed by PACl and POCl; TACl exhibited the poorest outcome. The presence of $\mathrm{TACl}$ and the National Institutes of Health Stroke Scale (NIHSS) scores were independent predictors of poor outcome. These findings were the same as those in middle-aged and old stroke $[19,20]$. The 40 cases of young IS studied by Khan et al., included 40\% TACl, $12.5 \% \mathrm{PACl}, 42.5 \%$ $\mathrm{LACl}$ and $5 \% \mathrm{POCl}$, in which there were more cases of major stroke (TACI) [22]. However, our study had more cases of $\mathrm{PACl}$ and $\mathrm{LACl}$ and fewer numbers of $\mathrm{TACl}$, which suggested a greater prevalence of moderate and minor stroke among the local young people, and thus a better prognosis.

Generally, $\mathrm{LACl}$ is the most common form of IS and has a good outcome. LACl accounted for $75 \%$ of cases in the cilostazol stroke prevention study from Japan [23], and also reached a majority in China [24]. The ratios of $L A C l$ seem to be broadly similar around the world, except for Argentina, Australia and Switzerland according to Shinohara's study [25] However, our and other's study indicated the dissimilar ratios of $\mathrm{LACl}$ in young IS $[21,22]$.

The TOAST classification has been widely used to classify the aetiology of IS. Only just reports from 2002 to 2012 years have shown a great diversity in TOAST subtypes in young IS patients (Table 5) [26-39]. In addition to differences in research design, areas, composition and sources of patients, sample size, and other factors, it was assumed that this diversity also may be due to the fact that the aetiology of young stroke is more complex than that of elderly patients and that the TOAST classification is not suitable for young stroke [40]. A previous study showed that nontraditional causes including dissections and thrombophilias were the most frequent in distribution of aetiologies by TOAST in young IS [40]. Another study on IS of unusual cause enrolled 70 patients and showed hematological disorders in 17 cases, infection in 11 , migraine stroke in 10 , cerebral infarction secondary to venous thrombosis in 9, primary inflammatory vascular conditions in 6 and miscellaneous causes in 17, and an age of 45 years or less was one of independent predictors of the stroke [41]. Our study displayed the most cases of SAO, followed by SUE, LAA, CE and SOE, which suggested that hypertension and diabetes mellitus are primary risk factors and that more cryptogenic stroke occurs in the local young IS patients. Most of the patients came from inland, and their eating habits and inadequate aetiology testing may have 
contributed to these results. The different aetiologies of stroke could affect the long-term mortality and recurrence of stroke, but these aetiologies are not related to long-term functional recovery [42].

Retrospective analysis was the primary shortcoming of our study. Therefore, it was difficult to avoid missing or inaccurate data, coupled with the fact that the TOAST classification may be unsuitable for young stroke, which limited the precision of the study results. We hope that prospective research will compensate for the shortcoming in the future. Nevertheless, our study used the largest sample size among similar studies in China, the study results are valid as a reference for the prevention and treatment of young stroke in the local population because the patients came from the two largest hospitals in the locality.

In conclusion, there were four stroke types in our study sample from the city of Zhuhai, including many cases of IS and $\mathrm{ICH}$ and fewer cases of SAH and MS. Most of the IS subtypes included $\mathrm{PACl}$ and $\mathrm{LACl}$ or SAO and SUE.

\section{List of Abbreviations}

CT: Computed Tomography

MRI: Magnetic Resonance Imaging

CTA: Computed tomographic angiography

MRA: Magnetic resonance angiogram

DSA: Digital subtraction angiography

IS: Ischemic stroke

$\mathrm{ICH}$ : Intracerebral haemorrhage

SAH: Subarachnoid haemorrhage

MS: Mixed stroke

OCSP: Oxfordshire Community Stroke Project

TOAST: Trial of Org 10172 in Acute Stroke Treatment

TACl: Total anterior circulation infarcts

PACI: Partial anterior circulation infarcts

LACI : Lacunar infarcts

POCI: Posterior circulation infarcts

LAA: Large-artery atherosclerosis

CE: Cardioembolism

SAO: Small-artery occlusion

SOE: Stroke of other determined aetiologies

SUE: Stroke of undetermined aetiology

\section{Competing interests}

The authors declare that they have no competing interests.

\section{Authors' contributions}

Li Z suggested the concept and design this work, and wrote manuscript. Wang J participated in the design of this work and writing the manuscript, and performed the data collection. Luo S participated in the design of this work and performed OCSP classification of stroke. Wei J helped to draft the manuscript and performed TOAST classification of stroke. Hu X performed the statistical analysis.

\section{Acknowledgement}

The medical records in this study were supplied by the medical record libraries of our hospital and Zhuhai People's Hospital. Wenyan Zhuo helped in supplying the medical records from Zhuhai People's Hospital.

\section{Publication history}

Editors: Adria Arboix Damunt, University of Barcelona, Spain. Fabrizio Sallustio, University of Rome Tor Vergata, Italy.
EIC: Tadanori Tomita, Northwestern University Feinberg School of Medicine, USA.

Received: 04-May-2013 Revised: 29-May-2013

Accepted: 07-Jun-2013 Published: 17-Jun-2013

\section{References}

1. Wang W, Zhao D and Wu G: The trend of incidence rate of acute stroke event in urban areas, Beijing from 1984 to 1999. Zhonghua Liu Xing Bing Xue Za Zhi 2001, 22:269-72. I PubMed

2. Zhang $X H$, Guan T, Mao J and Liu L: Disparity and its time trends in stroke mortality between urban and rural populations in China 1987 to 2001: changing patterns and their implications for public health policy. Stroke 2007, 38:3139-44. | Article | PubMed

3. George MG, Tong X, Kuklina EV and Labarthe DR: Trends in stroke hospitalizations and associated risk factors among children and young adults, 1995-2008. Ann Neurol 2011, 70:713-21. | Article I PubMed

4. Kittner SJ: Stroke in young adults: progress and opportunities. Neuroepidemiology 1998, 17:174-8. | Article | PubMed

5. Arnold M, Halpern M, Meier N, Fischer U, Haefeli T, Kappeler L, Brekenfeld C, Mattle HP and Nedeltchev K: Age-dependent differences in demographics, risk factors, co-morbidity, etiology, management, and clinical outcome of acute ischemic stroke. J Neurol 2008, 255:1503-7. | Article | PubMed

6. Wei JW, Arima H, Huang Y, Wang JG, Yang Q, Liu Z, Liu M, Lu C, Heeley EL, Anderson $C$ and ChinaQUEST Investigators: Variation in the frequency of intracerebral haemorrhage and ischaemic stroke in China: a national, multicentre, hospital register study. Cerebrovasc Dis 2010, 29:321-7. | Article I PubMed

7. Jiang B, Wang WZ, Chen H, Hong Z, Yang QD, Wu SP, Du XL and Bao QJ: Incidence and trends of stroke and its subtypes in China: results from three large cities. Stroke 2006, 37:63-8. | Article | PubMed

8. Amarenco P, Bogousslavsky J, Caplan LR, Donnan GA and Hennerici MG: Classification of stroke subtypes. Cerebrovasc Dis 2009, 27:493-501. Article I PubMed

9. Caplan LR: Stroke classification: a personal view. Stroke 2011, 42:S3-6. | Article I PubMed

10. Tunstall-Pedoe H: MONICA monograph and multimedia sourcebook: world's largest study of heart disease, stroke, risk factors, and population trends 1979-2002. World Health Organization 2003. I Pdf

11. Adams HP, Jr., Butler MJ, Biller J and Toffol GJ: Nonhemorrhagic cerebral infarction in young adults. Arch Neurol 1986, 43:793-6. | Article | PubMed

12. Bamford J, Sandercock P, Dennis M, Burn J and Warlow C: Classification and natural history of clinically identifiable subtypes of cerebral infarction. Lancet 1991, 337:1521-6. | Article | PubMed

13. Adams HP, Jr., Bendixen BH, Kappelle LJ, Biller J, Love BB, Gordon DL and Marsh EE, 3rd: Classification of subtype of acute ischemic stroke. Definitions for use in a multicenter clinical trial. TOAST. Trial of Org 10172 in Acute Stroke Treatment. Stroke 1993, 24:35-41. | Article | PubMed

14. Marini C, Russo T and Felzani G: Incidence of stroke in young adults: a review. Stroke Res Treat 2010, 2011:535672. I Article I PubMed Abstract | PubMed Full Text

15. Wu Z, Yao C, Zhao D, Wu G, Wang W, Liu J, Zeng Z and Wu Y: SinoMONICA project: a collaborative study on trends and determinants in cardiovascular diseases in China, Part i: morbidity and mortality monitoring. Circulation 2001, 103:462-8. | Article | PubMed

16. Arboix A, Comes E, Garcia-Eroles L, Massons J, Oliveres M, Balcells M and Targa C: Site of bleeding and early outcome in primary intracerebral hemorrhage. Acta Neurol Scand 2002, 105:282-8. I Article I PubMed

17. Bi Q and Beijing Neurdogist Club: Study on the risk factors among stroke in young people. Zhonghua Liu Xing Bing Xue Za Zhi 2003, 24:106-8. I PubMed

18. Huang RX and Zhong ST: Atherosclerotic mixed stroke. Zhongguo shen jing jing shen ji bing za zhi 1989, 15: 194-7. I Website 
Li et al. Neuroscience Discovery 2013,

19. Sprigg N, Gray LJ, Bath PM, Lindenstrom E, Boysen G, De Deyn PP, Friis P, Leys D, Marttila R, Olsson JE, O'Neill D, Ringelstein EB, van der Sande JJ , Turpie Aand TAIST Investigators: Stroke severity, early recovery and outcome are each related with clinical classification of stroke: data from the 'Tinzaparin in Acute Ischaemic Stroke Trial' (TAIST). J Neurol Sci 2007, 254:54-9. | Article | PubMed

20. Pittock SJ, Meldrum D, Hardiman O, Thornton J, Brennan P and Moroney JT: The Oxfordshire Community Stroke Project classification: correlation with imaging, associated complications, and prediction of outcome in acute ischemic stroke. J Stroke Cerebrovasc Dis 2003, 12:1-7. | Article | PubMed

21. Nedeltchev K, der Maur TA, Georgiadis D, Arnold M, Caso V, Mattle HP, Schroth G, Remonda L, Sturzenegger M, Fischer U and Baumgartner RW: Ischaemic stroke in young adults: predictors of outcome and recurrence. J Neurol Neurosurg Psychiatry 2005, 76:191-5. | Article | PubMed Abstract | PubMed Full Text

22. Khan FY, Yasin M, Abu-Khattab M, El Hiday AH, Errayes M, Lotf AK, Ibrahim AS, Abbas MT, Matar I, Alsamawi M and Alhail H: Stroke in Qatar: a first prospective hospital-based study of acute stroke. J Stroke Cerebrovasc Dis 2008, 17:69-78. | Article I PubMed

23. Gotoh F, Tohgi H, Hirai S, Terashi A, Fukuuchi $Y$, Otomo E, Shinohara Y, Itoh E, Matsuda T, Sawada T, Yamaguchi T, Nishimaru K and Ohashi Y: Cilostazol stroke prevention study: A placebo-controlled doubleblind trial for secondary prevention of cerebral infarction. J Stroke Cerebrovasc Dis 2000, 9:147-57. | Article

24. Li W, Lu M, Feng SJ, Li WZ, Wu B, Fang Y, Wang LC, Zhao SY, Zhao MY and Zhang ST: [Clinical characteristics and long-term prognosis of patients with ischemic and hemorrhagic stroke]. Zhonghua Yi Xue Za Zhi 2008 88:892-7. I PubMed

25. Shinohara Y: Regional differences in incidence and management of stroke - is there any difference between Western and Japanese guidelines on antiplatelet therapy? Cerebrovasc Dis 2006, 21 Suppl 1:1724. | Article | PubMed

26. Lee TH, Hsu WC, Chen CJ and Chen ST: Etiologic study of young ischemic stroke in Taiwan. Stroke 2002, 33:1950-5. | Article | PubMed

27. Cerrato P, Grasso M, Imperiale D, Priano L, Baima C, Giraudo M, Rizzuto A, Azzaro C, Lentini A and Bergamasco B: Stroke in young patients: etiopathogenesis and risk factors in different age classes. Cerebrovasc Dis 2004, 18:154-9. | Article | PubMed

28. Ghandehari K and Moud ZI: Incidence and etiology of ischemic stroke in Persian young adults. Acta Neurol Scand 2006, 113:121-4. | Article | PubMed

29. Rasura M, Spalloni A, Ferrari M, De Castro S, Patella R, Lisi F and Beccia M: A case series of young stroke in Rome. Eur J Neurol 2006, 13:146-52. | Article | PubMed

30. Wang HX., Wang Y, Li JJ and Hong H: The etiologies, risk factors and the imaging features of ischemic stroke in young adults: analysis of $\mathbf{4 1}$ cases. Zhongguo shen jing jing shen ji bing za zhi, 2008, 24:479-82. | Website

31. Ding JP and Su YY: Analysis of the causes and risk factors of cerebra I infarction in young adults. Zhongguo nao xue guan bing za zhi 2008, 5:202-6. | Website

32. Zheng Z.and Liu Y.F: Analysis of the causes and risk factors of cerebral arterial thrombosis in young adults. Zhonghua quan ke yi xue 2009, 7:7 -8. | Website

33. Putaala J, Curtze S, Hiltunen S, Tolppanen $\mathrm{H}$, Kaste $\mathrm{M}$ and Tatlisumak T: Causes of death and predictors of 5-year mortality in young adults after first-ever ischemic stroke: the Helsinki Young Stroke Registry. Stroke 2009, 40:2698-703. | Article | PubMed

34. Putaala J, Haapaniemi E, Metso AJ, Metso TM, Artto V, Kaste M and Tatlisumak T: Recurrent ischemic events in young adults after first-ever ischemic stroke. Ann Neurol 2010, 68:661-71. | Article | PubMed

35. Dharmasaroja PA, Muengtaweepongsa S, Lechawanich $C$ and Pattaraarchachai J: Causes of ischemic stroke in young adults in Thailand: a pilot study. J Stroke Cerebrovasc Dis 2011, 20:247-50. | Article I PubMed

36. Putaala J, Haapaniemi E, Kurkinen M, Salonen O, Kaste M and Tatlisumak
T: Silent brain infarcts, leukoaraiosis, and long-term prognosis in young ischemic stroke patients. Neurology 2011, 76:1742-9. | Article | PubMed

37. Chatzikonstantinou A, Wolf ME and Hennerici MG: Ischemic stroke in young adults: classification and risk factors. J Neurol 2012, 259:653-9. I Article I PubMed

38. Groppo E, De Gennaro R, Granieri G, Fazio P, Cesnik E, Granieri E and Casetta I: Incidence and prognosis of stroke in young adults: a population-based study in Ferrara, Italy. Neurol Sci 2012, 33:53-8. | Article | PubMed

39. Cotter PE, Belham M and Martin PJ: Towards understanding the cause of stroke in young adults utilising a new stroke classification system (A-SC-O). Cerebrovasc Dis 2012, 33:123-7. I Article I PubMed

40. Telman G, Kouperberg E, Sprecher E and Yarnitsky D: Distribution of etiologies in patients above and below age $\mathbf{4 5}$ with first-ever ischemic stroke. Acta Neurol Scand 2008, 117:311-6. | Article | PubMed

41. Arboix A, Bechich S, Oliveres M, Garcia-Eroles L, Massons J and Targa $C$ : Ischemic stroke of unusual cause: clinical features, etiology and outcome. Eur J Neurol 2001, 8:133-9. | Article | PubMed

42. Varona JF: Long-term prognosis of ischemic stroke in young adults Stroke Res Treat 2010, 2011:879817. | Article | PubMed Abstract | PubMed Full Text

\section{Citation:}

Li Z, Wang J, Luo S, Wei J and Hu X: Classification analysis of young stroke in zhuhai city, China. Neuroscience Discovery 2013, 1:2.

http://dx.doi.org/10.7243/2052-6946-1-2 